\title{
Modal variety of microsatellite instability in human endometrial carcinomas
}

\author{
Takako Eto $^{1} \cdot{\text { Yan } \mathrm{Zhao}^{2}}^{2}$ Akiko Maruyama $^{1} \cdot$ Kaname Miyashita $^{3} \cdot$ Aiko Yasui $^{4}$. \\ Seiki Nakao $^{4} \cdot$ Kenichi Taguchi $^{4} \cdot$ Mototsugu Shimokawa $^{4} \cdot$ Shinya Oda $^{4}$. \\ Toshiaki Saito ${ }^{1}$
}

Received: 12 May 2015 / Accepted: 7 August 2015 / Published online: 23 August 2015

(C) The Author(s) 2015. This article is published with open access at Springerlink.com

\begin{abstract}
Purpose Microsatellite instability (MSI) in human endometrial cancer (EC) was analysed using a unique fluorescent technique. MSI is associated with various human neoplasms. However, the reported frequency of MSI differs widely in each malignancy. Methodological difficulties have in fact been pointed out in its assay techniques.

Methods We previously established a sensitive fluorescent technique in which the major methodological problems are overcome. Application of this technique has revealed two distinct modes of microsatellite alterations, i.e. Type A and Type B. In the present study, we have applied this technique to 94 ECs.

Results Significant microsatellite alterations were observed in 38 (40.4\%) tumours of the panel. The two modes, Type A and Type B, were indeed observed in this malignancy. More importantly, we found that the modes more closely correlated with the molecular and
\end{abstract}

Electronic supplementary material The online version of this article (doi:10.1007/s00432-015-2030-2) contains supplementary material, which is available to authorized users.

Shinya Oda

soda@nk-cc.go.jp

1 Gynecology Service, National Kyushu Cancer Center, Fukuoka 811-1395, Japan

2 The Third Surgery Department, Liaoning Cancer Hospital and Institute, Shenyang 110042, The People's Republic of China

3 Department of Medicine and Bioregulatory Science, Graduate School of Medical Sciences, Kyushu University, Fukuoka 812-8582, Japan

4 Clinical Research Institute, National Kyushu Cancer Center, Fukuoka 811-1395, Japan clinicopathological backgrounds of the tumours than the established and widely used MSI grades, MSI-H and MSIL. Type B MSI widely correlated with family history of hereditary non-polyposis colorectal cancer-associated cancers, whereas MSI-H only did with that of colorectal cancer. Furthermore, mutation in the KRAS oncogene, which has been regarded as generally infrequent in microsatelliteunstable tumours, was clearly associated with Type A MSI. Conclusions Our observations may suggest a biological relevance and a potential utility of the modal classification of MSI and, furthermore, added complexities to genomic instability underlying tumourigenesis in human endometrium.

Keywords Microsatellite instability · DNA mismatch repair $\cdot$ Endometrial cancer $\cdot$ KRAS mutation $\cdot$ Familial predisposition

\section{Background}

Somatic instability of repetitive DNA sequences comprising minimal reiterative motifs, i.e. microsatellite instability (MSI), has initially been reported in tumours arising in Lynch syndrome [LS, alias hereditary non-polyposis colorectal cancer (HNPCC)] patients (Aaltonen et al. 1993), in which germline mutations in the genes functioning in DNA mismatch repair (MMR) are often found. MMR is an important cellular system that counteracts replication errors caused by DNA polymerases and, consequently, guarantees the high fidelity of DNA replication on the genome. Repetitive sequences such as microsatellites are particularly prone to replication errors, because DNA polymerases often slip on the repetitive sequences, and strand misalignment is formed. These replication errors, if uncorrected, are fixed 
during subsequent replication as addition or deletion of one or more repeat units. Thus, the phenomenon of MSI has been considered to reflect MMR deficiency in tumour cells. As MSI is frequently observed in various human neoplasms (Arzimanoglou et al. 1998), analyses of MSI have been prevalent in the fields of oncology or pathology. Numerous studies have been done on a wide variety of human malignancies and addressed the characteristics of $\mathrm{MSI}^{+}$tumours.

The reported frequency for $\mathrm{MSI}^{+}$tumours in each malignancy, however, differs widely in the literature. In order to manage the confusion raised in the field, the National Cancer Institute (NCI) sponsored the workshop, 'Microsatellite Instability and RER Phenotypes in Cancer Detection and Familial Predisposition' (Boland et al. 1998) in 1997, which concluded that the variety of microsatellites used was a major cause of discrepancies among data from various laboratories and, consequently, recommended a panel of five microsatellites as a 'working reference panel'. In addition, the NCI workshop recommended that the $\mathrm{MSI}^{+}$phenotype should be classified into two different grades, i.e. MSI-H (high) and MSI-L (low), according to the frequencies of changes in a defined set of microsatellite markers. However, the diversity of data in the literature has not improved since then. Analysis of MSI is now commonplace, but several methodological problems have in fact been pointed out in the conventional assay techniques (Maehara et al. 2001) and may also account for the variability in results. We previously established a unique fluorescent technique designated as high-resolution fluorescent microsatellite analysis (HRFMA), in which products of polymerase chain reaction (PCR) are precisely and quantitatively resolved (Oda et al. 1997). In this technique, (a) electrophoretic profiles of microsatellites PCR products are simplified enzymatically or by primer sequence modifications, (b) each DNA fragment is detected quantitatively by use of an automated DNA sequencer, and (c) two differently labelled PCR products derived from tumour (red) and the corresponding normal tissues (green) are co-electrophoresed (see Fig. 1), in order to exclude migration errors. Application of this technique has revealed a number of previously unrecognised aspects of MSI in human cancer. In particular, we found two qualitatively distinct patterns of microsatellite alterations, i.e. Type A and Type B (Oda et al. 2005). Although this distinction has not widely been discussed, our previous data suggest that different molecular abnormalities may underlie these two modes of MSI (Oda et al. 2005). It is widely known that tumours exhibiting the MSI-H phenotype form a distinct entity with unique clinicopathological and molecular characteristics, particularly in colorectal cancer (Jass et al. 2002), and accordingly, two mutually exclusive pathways are hypothesised in colorectal tumourigenesis (Lengauer et al. 1998). Several reports, however, suggest that this distinction might be an oversimplification (Goel et al. 2003; Hawkins et al. 2001; Jass et al. 2002; Young et al. 2001). Attention has been drawn to the classification of the MSI phenotypes in human cancer.

Microsatellite alterations are most frequently observed in tumours occurring in LS kindred. More than $90 \%$ of LS tumours are $\mathrm{MSI}^{+}$(Liu et al. 1996). In the sporadic setting, endometrial carcinoma (EC) is one of the most microsatellite-unstable human neoplasms. EC indeed occurs in LS patients and is the second most frequent malignancy in LS. Numerous data have been collected on the microsatellite alterations observed in EC, and similarly to colorectal cancer, the MSI-H phenotype is now regarded as characteristic of a subset of ECs (Yeramian et al. 2013). However, also in $\mathrm{EC}$, the data accumulated in the literature are diverse (see Discussion). In addition, the Type A/B classification has not been applied in assessing MSI in ECs. Using our unique dual-colour fluorescent technique (Oda et al. 1997), we analysed microsatellite alterations in detail in a relatively large panel of tumours from EC patients and found that the two modes of MSI, i.e. Type A and Type B, are indeed observed in this malignancy. More importantly, the modes more closely correlated with the clinicopathological and molecular backgrounds of the tumours than the MSI$\mathrm{H} / \mathrm{L}$ grades, which suggests that, in addition to the established classification according to the frequencies of microsatellite changes, the modal classification may also be of potential use. Here, we report the modal variety of MSI in human endometrial cancer and its biological significance.

\section{Methods}

\section{Patients and tissue specimens}

Samples of cancer and the corresponding normal tissues were collected from consecutive $94 \mathrm{EC}$ patients who underwent surgery in Gynaecology Division of National Kyushu Cancer Center (NKCC) from 1997 to 2003. According to histopathological diagnosis, non-endometrioid-type tumours were excluded from the patient panel. This panel includes one LS patient who fulfilled Amsterdam Criteria II (Vasen et al. 1999). Specimens, taken immediately after resection, were placed in liquid nitrogen, and then stored at $-80{ }^{\circ} \mathrm{C}$.

\section{DNA extraction}

Tissue specimens were lysed in digestion buffer $(10 \mathrm{mM}$ Tris-Cl pH 8.0, 0.1 M EDTA pH 8.0, 0.5 \% SDS, $20 \mu \mathrm{g} /$ $\mathrm{ml}$ pancreatic RNase). After treatment with proteinase $\mathrm{K}$ and extraction with phenol, DNA was precipitated with ethanol, then dissolved in $1 \mathrm{X}$ TE $(10 \mathrm{mM}$ Tris-Cl $\mathrm{pH} 7.5$, 
Fig. 1 Microsatellite alterations observed in human endometrial cancer. Using genomic DNA samples prepared from tumour and the corresponding normal tissues, microsatellite sequences, indicated at the right top of each panel, were independently amplified by PCR with differentially labelled primers, then mixed and co-electrophoresed in an automated DNA sequencer. Representative results are shown and detected microsatellite alterations are indicated by arrows: red lines cancer, green lines normal tissues, a negative cases, b Type A MSI, c Type B MSI, $\mathbf{d}$ cases suspected for LOH. Data in cases of separate and inseparable heterozygous microsatellites are shown in left and right columns, respectively. Patient codes corresponding to those used in Table 1 are also indicated at the right of each panel
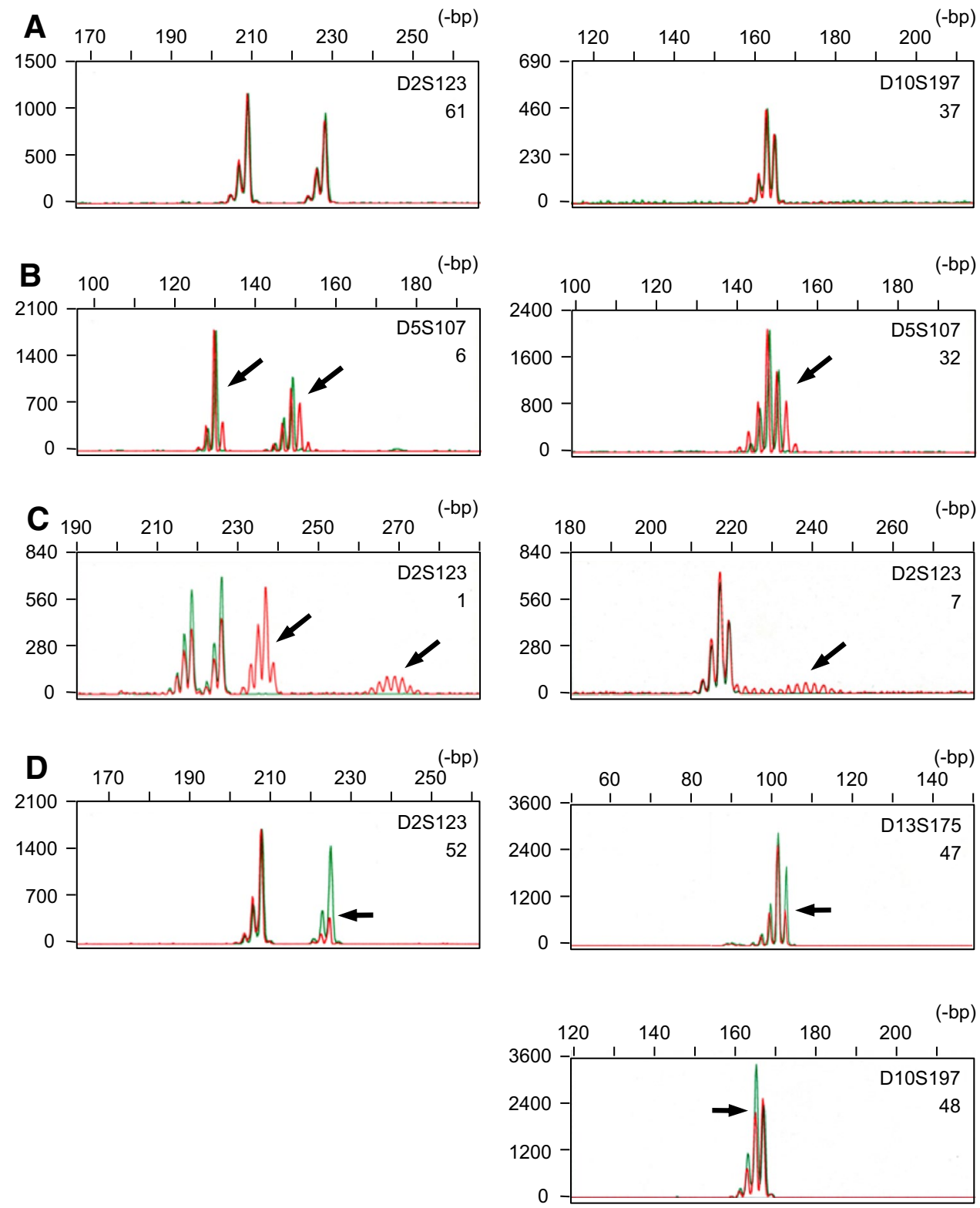

$1 \mathrm{mM}$ EDTA). The concentration of DNA was determined by $\mathrm{OD}_{260}$ using a spectrophotometer. The quality of DNA was checked by agarose gel electrophoresis.

\section{Microsatellite instability}

Microsatellite analysis using fluorescence-labelled primers and an automated DNA sequencer has been described in detail (Oda et al. 1997). Briefly, five selected human dinucleotide microsatellites, D2S123, D5S107, D10S197, D11S904 and D13S175 (Oki et al. 1999), were amplified by polymerase chain reaction (PCR). Mononucleotide microsatellites were not used in order to exclude the influence of the terminal deoxynucleotidyl transferase (TDT) activity of thermostable DNA polymerases (see
Discussion). Forward primers were labelled with the fluorescent compound, 6-FAM (6-carboxyfluorescein) or HEX (6-carboxy-2', 4', 7', 4, 7, hexachloro-fluorescein). TaKaRa Taq (Takara Bio Inc., Otsu, Japan) was used as a thermostable polymerase. To compare the electrophoretic profiles between two samples, 6-FAM-labelled products and HEXlabelled products were mixed and co-electrophoresed in the ABI310 sequencer (Life Technologies, Carlsbad, CA, USA). The data were processed using the GeneScan software (Life Technologies).

\section{DNA sequencing}

All the exons and exon-intron junctions of $M S H 2$ and $M L H 1$ were amplified by PCR using Taq polymerase with 
$3^{\prime}$ exonuclease activity, TaKaRa Ex Taq ${ }^{\mathrm{TM}}$ (Takara Bio Inc.). The sequencing strategy used is the same as the one reported by Kolodner Kolodner et al. (1994, 1995), except that the sequence complementary for M13 universal primer was deleted from each of the primer sequences, and that one-step PCR was employed. PCR products were used as a template for cycle sequencing reactions using BigDye Terminator Cycle Sequencing Kit (Life Technologies). Mutations found in one PCR product were verified by reverse sequencing and finally confirmed in two independently amplified PCR products.

The 107-bp region in the exon 2 of the KRAS gene that encompasses the mutation hotspots, codons 12 and 13, was amplified by PCR using 'c-Ki-ras/12 primer set' ('c-Ki-ras/12 forward', 5'-GACTGAATATAAACTTGTGG; 'c-Ki-ras/12 reverse', 5'-CTATTGTTGGATCATATTCG) (Takara Bio Inc.) and TaKaRa Ex Taq ${ }^{\mathrm{TM}}$ (Takara Bio Inc.). PCR products were directly used as a template for cycle sequencing reactions using BigDye terminator cycle sequencing kit (Life Technologies). The reverse primer, 'c-Ki-ras/12 reverse', was used for cycle sequencing reactions. Mutations found in one PCR product were verified by sequencing using our original inner primer that is $5^{\prime}$-adjacent to 'c-Ki-ras/12 reverse', KRAS2EX2R2 ( $5^{\prime}$-TCCACAAAATGATTCTGAATTAGC), and finally confirmed in three independently amplified PCR products.

\section{Immunohistochemistry}

Tissue specimens were fixed in buffered $10 \%$ formaldehyde and embedded in paraffin. Prior to the assay, the specimens were sectioned at $4 \mu \mathrm{m}$ and deparaffinised using xylene. Antigen retrieval was done by heating the sections in citrate buffer. Endogenous peroxidase activity was blocked by incubation in $3.0 \% \mathrm{H}_{2} \mathrm{O}_{2}$. Non-specific protein binding was inhibited by incubation in $10 \%$ normal goat serum. The sections were reacted with an adequately diluted antiMSH2 mouse monoclonal antibody, clone GB12 (Calbiochem Novabiochem-Oncogen, Oncogen Research Products, Cambridge, MA, USA), or an anti-MLH1 antibody, clone 14 (Calbiochem Novabiochem-Oncogen, Oncogen Research Products) at $4{ }^{\circ} \mathrm{C}$ overnight. The sections were next reacted with biotinylated goat anti-mouse IgG antibody (Dako Denmark A/S, Glostrup, Denmark) and then with peroxidaselabelled streptavidin (Dako Denmark A/S). Finally, the sections were incubated with diaminobenzidine and $\mathrm{H}_{2} \mathrm{O}_{2}$. Counterstaining was done using Mayer's haematoxylin. Negative control experiments were also performed by replacing the primary antibodies with a non-specific mouse IgG.

\section{Statistical analysis}

Fisher's exact probability test was used in all the statistical analyses.

\section{Results}

\section{High-resolution fluorescent microsatellite analysis (HRFMA) reveals the modal variety of microsatellite instability in endometrial cancer}

In $\mathrm{MSI}^{+}$tumours, changes in microsatellite lengths are sometimes minor and as small as loss or gain of a single repeat unit, and cells carrying microsatellite changes are not always major in a given sample. However, using HRFMA, such minor and subtle alterations are sensitively and quantitatively detected, and results are highly reproducible in several independent experiments. We have applied this technique for MSI analyses in a panel of 94 $\mathrm{ECs}$, in order to analyse microsatellite alterations in this malignancy in detail. The system sensitively detected various microsatellite changes. Examples are shown in Fig. 1. The basic electrophoretic profile of PCR-amplified dinucleotide microsatellite sequences is a cluster of three two base-pitched peaks. In human populations, microsatellites are highly polymorphic and, therefore, the parental alleles are different in length in many cases. In such cases, two peak clusters are separate (Fig. 1a, left) or, sometimes, partially overlap (Fig. 1a, right). Abnormal microsatellite length changes in cancer cells are detected as appearance of new peaks or changes in the peak heights in the electrophoretic profiles (Fig. 1, red lines). In the analyses of ECs, microsatellite length alterations were relatively small and within 6-bp in some cases (Fig. 1b). In the other, more drastic changes involving longer than 6-bp were also observed (Fig. 1c). We have designated the former type of microsatellite alterations as Type A and the latter as Type B in our previous observations (Oda et al. 2005). As Type $\mathrm{B}$ alterations involve large and, sometimes, discontinuous differences in microsatellite length, it can appear as if 'new' alleles, in addition to the parental alleles, are present (Fig. 1c). In EC, this type of microsatellite changes were frequently observed (Table 1), which is in clear contrast to other malignancies including colorectal cancer (Ikeda et al. 2001). In DNA fragment analyses using an automated sequencer, loss of heterozygosity ( $\mathrm{LOH})$ is also detectable (Fig. 1d, left), but some patterns of peak clusters are theoretically indistinguishable between MSI and LOH (Fujii et al. 2009) (Fig. 1d, right). These cases are indicated as 'LOH" in Table 1. Despite minimised false positives, significant microsatellite alterations were observed in a considerable number of the subjects of the panel, and, consequently, the frequency of $\mathrm{MSI}^{+}$tumours has been estimated to be $40.4 \%$ (38/94). According to the established NCI guideline, the $\mathrm{MSI}^{+}$ECs were also classified into MSI-H and MSI-L (Table 1). The frequencies for MSI-H and MSI-L were $37.2 \%$ (35/94) and $3.2 \%$ (3/94), respectively. 
Table 1 Microsatellite alterations observed n 94 endometrioid endometrial cancer patients

\begin{tabular}{|c|c|c|c|c|c|c|c|}
\hline \multirow[t]{2}{*}{ Patient code } & \multicolumn{5}{|c|}{ Microsatellite } & \multirow[t]{2}{*}{ MSI A/B } & \multirow[t]{2}{*}{ MSI-H/L } \\
\hline & $\mathrm{D} 2 \mathrm{~S}$ & D5S & D10S & D11S & D13S & & \\
\hline 1 & $\mathrm{~B}$ & $\mathrm{~B}$ & $\mathrm{~B}$ & - & B & B & $\mathrm{H}$ \\
\hline 2 & $\mathrm{~B}$ & $\mathrm{~B}$ & $\mathrm{~B}$ & $\mathrm{~A}$ & - & $\mathrm{B}^{\mathrm{a}}$ & $\mathrm{H}$ \\
\hline 3 & $\mathrm{~B}$ & $\mathrm{~B}$ & $\mathrm{~B}$ & A & A & B & $\mathrm{H}$ \\
\hline 4 & $\mathrm{~B}$ & $\mathrm{~B}$ & $\mathrm{~B}$ & A & B & $\mathrm{B}$ & $\mathrm{H}$ \\
\hline 5 & A & $\mathrm{B}$ & B & A & B & B & $\mathrm{H}$ \\
\hline 6 & $\mathrm{~B}$ & A & $\mathrm{B}$ & - & $\mathrm{B}$ & $\mathrm{B}$ & $\mathrm{H}$ \\
\hline 7 & B & $\mathrm{B}$ & B & A & B & B & $\mathrm{H}$ \\
\hline 8 & $\mathrm{~B}$ & $\mathrm{~B}$ & $\mathrm{~B}$ & A & $\mathrm{B}$ & B & $\mathrm{H}$ \\
\hline 9 & $\mathrm{~B}$ & A & $\mathrm{B}$ & - & $\mathrm{B}$ & $\mathrm{B}$ & $\mathrm{H}$ \\
\hline 10 & A & A & $\mathrm{B}$ & A & $\mathrm{B}$ & $\mathrm{B}$ & $\mathrm{H}$ \\
\hline 11 & A & B & $\mathrm{B}$ & - & A & $\mathrm{B}$ & $\mathrm{H}$ \\
\hline $12^{\mathrm{b}}$ & B & $\mathrm{B}$ & A & A & A & B & $\mathrm{H}$ \\
\hline 13 & $\mathrm{~B}$ & A & B & - & A & B & $\mathrm{H}$ \\
\hline 14 & A & $\mathrm{B}$ & $\mathrm{B}$ & - & A & $\mathrm{B}$ & $\mathrm{H}$ \\
\hline 15 & A & B & B & A & - & B & $\mathrm{H}$ \\
\hline 16 & B & A & B & A & - & B & $\mathrm{H}$ \\
\hline 17 & B & - & A & - & B & B & $\mathrm{H}$ \\
\hline 18 & A & B & B & A & A & B & $\mathrm{H}$ \\
\hline 19 & A & A & B & A & B & B & $\mathrm{H}$ \\
\hline 20 & B & A & A & - & $\mathrm{A}$ & B & $\mathrm{H}$ \\
\hline 21 & A & A & B & A & A & B & $\mathrm{H}$ \\
\hline 22 & $\mathrm{~A}$ & A & B & $\mathrm{A}$ & A & B & $\mathrm{H}$ \\
\hline 23 & A & A & B & A & A & B & $\mathrm{H}$ \\
\hline 24 & $\mathrm{~A}$ & B & A & A & A & B & $\mathrm{H}$ \\
\hline 25 & B & A & A & A & A & B & $\mathrm{H}$ \\
\hline 26 & B & A & A & $\mathrm{A}$ & - & B & $\mathrm{H}$ \\
\hline 27 & B & A & $\mathrm{A}$ & - & A & B & $\mathrm{H}$ \\
\hline 28 & A & A & A & - & B & B & $\mathrm{H}$ \\
\hline 29 & $\mathrm{~A}$ & A & B & - & - & B & $\mathrm{H}$ \\
\hline 30 & A & B & A & - & A & B & $\mathrm{H}$ \\
\hline 31 & A & A & A & - & A & A & $\mathrm{H}$ \\
\hline 32 & A & A & A & A & - & A & $\mathrm{H}$ \\
\hline 33 & A & A & $\mathrm{LOH}^{\mathrm{c}}$ & A & A & A & $\mathrm{H}$ \\
\hline 34 & $\mathrm{~A}$ & - & - & A & A & $\mathrm{A}$ & $\mathrm{H}$ \\
\hline 35 & A & - & A & - & - & A & $\mathrm{H}$ \\
\hline 36 & A & - & - & - & - & A & $\mathrm{L}$ \\
\hline 37 & A & - & - & $\mathrm{LOH}^{\prime}$ & - & A & $\mathrm{L}$ \\
\hline 38 & $\mathrm{LOH}$ & A & - & - & - & A & $\mathrm{L}$ \\
\hline 39 & & LOH' & - & - & - & $\mathrm{N}$ & S \\
\hline 40 & - & - & - & - & LOH' & $\mathrm{N}$ & S \\
\hline 41 & - & LOH' & $\mathrm{LOH}^{\prime}$ & - & - & $\mathrm{N}$ & $S$ \\
\hline 42 & - & - & - & $\mathrm{LOH}^{\prime}$ & - & $\mathrm{N}$ & $S$ \\
\hline 43 & $\mathrm{LOH}^{\prime}$ & - & - & - & - & $\mathrm{N}$ & S \\
\hline 44 & LOH' & LOH' & - & - & LOH' & $\mathrm{N}$ & S \\
\hline 45 & - & $\mathrm{LOH}^{\prime}$ & - & $\mathrm{LOH}$ & - & $\mathrm{N}$ & S \\
\hline 46 & - & $\mathrm{LOH}$ & - & - & $\mathrm{LOH}^{\prime}$ & $\mathrm{N}$ & $S$ \\
\hline 47 & - & $\mathrm{LOH}$ & LOH' & LOH & LOH' & $\mathrm{N}$ & S \\
\hline 48 & $\mathrm{LOH}$ & - & LOH' & - & - & $\mathrm{N}$ & S \\
\hline 49 & - & - & $\mathrm{LOH}$ & $\mathrm{LOH}$ & $\mathrm{LOH}^{\prime}$ & $\mathrm{N}$ & S \\
\hline 50 & $\mathrm{LOH}$ & - & $\mathrm{LOH}^{\prime}$ & - & - & $\mathrm{N}$ & S \\
\hline 51 & $\mathrm{LOH}$ & - & LOH' & - & - & $\mathrm{N}$ & S \\
\hline 52 & $\mathrm{LOH}$ & - & - & LOH & LOH' & $\mathrm{N}$ & S \\
\hline
\end{tabular}


Table 1 continued

\begin{tabular}{|c|c|c|c|c|c|c|c|}
\hline \multirow[t]{2}{*}{ Patient code } & \multicolumn{5}{|c|}{ Microsatellite } & \multirow[t]{2}{*}{ MSI A/B } & \multirow[t]{2}{*}{ MSI-H/L } \\
\hline & D2S & D5S & D10S & D11S & D13S & & \\
\hline 53 & $\mathrm{LOH}$ & - & - & - & - & $\mathrm{N}$ & S \\
\hline 54 & - & $\mathrm{LOH}$ & & $\mathrm{LOH}$ & - & $\mathrm{N}$ & S \\
\hline 55 & - & - & $\mathrm{LOH}$ & - & $\mathrm{LOH}$ & $\mathrm{N}$ & S \\
\hline 56 & - & - & - & - & $\mathrm{LOH}$ & $\mathrm{N}$ & S \\
\hline 57 & - & & $\mathrm{LOH}$ & - & - & $\mathrm{N}$ & S \\
\hline 58 & - & - & LOH & LOH & - & $\mathrm{N}$ & $\mathrm{S}$ \\
\hline 59 & - & - & $\mathrm{LOH}$ & - & - & $\mathrm{N}$ & S \\
\hline 60 & - & $\mathrm{LOH}$ & & - & - & $\mathrm{N}$ & S \\
\hline 61 & - & - & - & - & - & $\mathrm{N}$ & S \\
\hline 62 & - & - & - & - & - & $\mathrm{N}$ & S \\
\hline 63 & - & - & - & - & - & $\mathrm{N}$ & $\mathrm{S}$ \\
\hline 64 & - & - & - & - & - & $\mathrm{N}$ & S \\
\hline 65 & - & - & - & - & - & $\mathrm{N}$ & S \\
\hline 66 & - & - & - & - & - & $\mathrm{N}$ & S \\
\hline 67 & - & - & - & - & - & $\mathrm{N}$ & S \\
\hline 68 & - & - & - & - & - & $\mathrm{N}$ & $S$ \\
\hline 69 & - & - & - & - & - & $\mathrm{N}$ & $S$ \\
\hline 70 & - & - & - & - & - & $\mathrm{N}$ & $S$ \\
\hline 71 & - & - & - & - & - & $\mathrm{N}$ & $\mathrm{S}$ \\
\hline 72 & - & - & - & - & - & $\mathrm{N}$ & $S$ \\
\hline 73 & - & - & - & - & - & $\mathrm{N}$ & $S$ \\
\hline 74 & - & - & - & - & - & $\mathrm{N}$ & $S$ \\
\hline 75 & - & - & - & - & - & $\mathrm{N}$ & $S$ \\
\hline 76 & - & - & - & - & - & $\mathrm{N}$ & $S$ \\
\hline 77 & - & - & - & - & - & $\mathrm{N}$ & $S$ \\
\hline 78 & - & - & - & - & - & $\mathrm{N}$ & $S$ \\
\hline 79 & - & - & - & - & - & $\mathrm{N}$ & $\mathrm{S}$ \\
\hline 80 & - & - & - & - & - & $\mathrm{N}$ & $S$ \\
\hline 81 & - & - & - & - & - & $\mathrm{N}$ & $S$ \\
\hline 82 & - & - & - & - & - & $\mathrm{N}$ & $S$ \\
\hline 83 & - & - & - & - & - & $\mathrm{N}$ & $\mathrm{S}$ \\
\hline 84 & - & - & - & - & - & $\mathrm{N}$ & $S$ \\
\hline 85 & - & - & - & - & - & $\mathrm{N}$ & $S$ \\
\hline 86 & - & - & - & - & - & $\mathrm{N}$ & $S$ \\
\hline 87 & - & - & - & - & - & $\mathrm{N}$ & $\mathrm{S}$ \\
\hline 88 & - & - & - & - & - & $\mathrm{N}$ & $S$ \\
\hline 89 & - & - & - & - & - & $\mathrm{N}$ & $S$ \\
\hline 90 & - & - & - & - & - & $\mathrm{N}$ & $S$ \\
\hline 91 & - & - & - & - & - & $\mathrm{N}$ & $\mathrm{S}$ \\
\hline 92 & - & - & - & - & - & $\mathrm{N}$ & $S$ \\
\hline 93 & - & - & - & - & - & $\mathrm{N}$ & $S$ \\
\hline 94 & - & - & - & - & - & $\mathrm{N}$ & $\mathrm{S}$ \\
\hline
\end{tabular}

MSI microsatellite instability, $A$ Type A MSI, $B$ Type B MSI, $H$ MSI-high, $L$ MSI-low, $I H C$ immunohistochemistry, + expressed, - no change/not expressed, $N D$ not done, $L O H$ loss of heterozygosity

a Tumours are classified as Type B when Type B alterations are observed in at least one marker

b The patient fulfilled Amsterdam Criteria II (Vasen et al. 1999), and a deleterious mutation (I586delT) of $M L H 1$ was found in the tumour. Sequence alterations were not detected in the other tumours

c Changes theoretically indistinguishable between MSI and LOH are indicated as 'LOH" (see text) 
Table 2 Relationship between MSI-H/L and Type A/B MSI

\begin{tabular}{llcc}
\hline & Type A & Type B & Subtotal \\
\hline MSI-H & 5 & 30 & 35 \\
MSI-L & 3 & 0 & 3 \\
Subtotal & 8 & 30 & 38 \\
\hline
\end{tabular}

$p=0.01$

Table 3 Clinicopathological variables and the NCI classification of MSI in endometrial cancer

\begin{tabular}{|c|c|c|c|c|}
\hline & \multicolumn{3}{|c|}{ MSI grade } & \multirow[t]{2}{*}{$p$ value } \\
\hline & MSI-L & MSI-H & MSS & \\
\hline Number of cases & 3 & 35 & 56 & \\
\hline \multicolumn{5}{|l|}{ Age } \\
\hline$\leq 55$ & 3 & 23 & 24 & \multirow[t]{2}{*}{0.02} \\
\hline$\geq 56$ & 0 & 12 & 32 & \\
\hline \multicolumn{5}{|l|}{ Stage } \\
\hline 1 & 2 & 24 & 39 & \multirow[t]{4}{*}{0.79} \\
\hline 2 & 0 & 0 & 2 & \\
\hline 3 & 1 & 9 & 14 & \\
\hline 4 & 0 & 2 & 1 & \\
\hline \multicolumn{5}{|l|}{ Grade } \\
\hline 1 & 0 & 14 & 23 & \multirow[t]{3}{*}{0.45} \\
\hline 2 & 2 & 12 & 24 & \\
\hline 3 & 1 & 9 & 9 & \\
\hline \multicolumn{5}{|l|}{ Survival } \\
\hline Alive & 3 & 33 & 47 & \multirow[t]{2}{*}{0.31} \\
\hline Dead & 0 & 2 & 9 & \\
\hline \multicolumn{5}{|l|}{ Family history } \\
\hline \multicolumn{5}{|l|}{ Any cancer } \\
\hline Yes & 1 & 22 & 30 & \multirow[t]{2}{*}{0.54} \\
\hline No & 2 & 13 & 26 & \\
\hline \multicolumn{5}{|l|}{ Colorectal cancer } \\
\hline Yes & 1 & 7 & 3 & \multirow[t]{2}{*}{0.03} \\
\hline No & 2 & 28 & 53 & \\
\hline \multicolumn{5}{|l|}{ Gastric cancer } \\
\hline Yes & 0 & 11 & 16 & \multirow[t]{2}{*}{0.70} \\
\hline No & 3 & 24 & 40 & \\
\hline \multicolumn{5}{|c|}{ HNPCC-associated cancers ${ }^{\mathrm{a}}$} \\
\hline Yes & 1 & 16 & 16 & \multirow[t]{2}{*}{0.20} \\
\hline No & 2 & 19 & 40 & \\
\hline \multicolumn{5}{|l|}{ Double cancer } \\
\hline Yes & 0 & 4 & 12 & \multirow[t]{2}{*}{0.43} \\
\hline No & 3 & 31 & 44 & \\
\hline \multicolumn{5}{|l|}{ Menopause } \\
\hline Before & 2 & 12 & 19 & \multirow[t]{2}{*}{0.58} \\
\hline After & 1 & 23 & 37 & \\
\hline
\end{tabular}

a Carcinomas in the colorectum, endometrium, ovary and stomach were scored as 'HNPCC-associated cancers' (Vasen et al. 1999). The other HNPCC-related tumours were not found in the patients' kindred
The relationships between MSI-H/L and Type A/B MSI are expressed in Table 2, which are highly parallel to the figure obtained in our previous observations of colorectal cancer (Ikeda et al. 2001).

\section{Type A/B MSI characterises endometrial carcinomas with unique clinicopathological and molecular backgrounds}

We next examined whether the observed microsatellite-unstable phenotypes correlated with common clinicopathological variables of the tumours. In $\mathrm{EC}$, the $\mathrm{MSI}^{+}$phenotype, particularly the MSI-H phenotype, has been reported to correlate with tumour grade, stage and patient survivals (see Supplementary Table). However, none of these parameters correlated with the MSI-H phenotype in this study (Table 3). Instead, we found a significant correlation with patient age and, more importantly, family history of colorectal cancer. This tendency was also confirmed in the Type A/B classification. The more important finding is that Type B MSI correlated not only with family history of colorectal cancer but also with that of 'HNPCC-associated cancers' (Vasen et al. 1999) (Table 4), which frequently arise in LS patients and includes, in addition to colorectal cancer and EC, carcinomas in the stomach, pancreas, small intestine, ovary and the biliary or urinary tracts and the specific types of tumours in the brain and the skin. The $\mathrm{MSI}^{+}$ phenotype is observed in more than $90 \%$ of LS tumours (Liu et al. 1996) and now regarded as a molecular hallmark of LS. The strong association between Type B MSI and HNPCCassociated cancers may suggest that the Type B phenotype may better reflect the biological backgrounds of the tumours.

The $\mathrm{MSI}^{+}$phenotype in EC has also been reported to correlate with various gene mutations or gene expression changes in cancer cells. We therefore tested whether Type A/B phenotypes correlated with these molecular abnormalities. The KRAS gene is one of the most frequently mutated oncogenes in various human malignancies and is indeed known to be mutated in EC. Several early studies have reported that KRAS mutation was significantly associated with the $\mathrm{MSI}^{+}$phenotype (Duggan et al. 1994; Lagarda et al. 2001). We therefore sequenced the genomic region of the KRAS gene that encompasses the most frequently mutated codons, i.e. codons 12 and 13, in the $\mathrm{MSI}^{+}$ tumours of our panel. KRAS mutation was found in five tumours. Intriguingly, KRAS mutation was more closely associated with Type A MSI than with MSI-H/L (Tables 5 and 6). This finding is consistent with our previous observation that KRAS mutation was frequently found in Type $\mathrm{A}$ colorectal tumours (Zhao et al. 2008). KRAS mutation was also frequent in tumours without family history of malignancies, although this tendency was not statistically significant $(p=0.07$, data not shown). 
Table 4 Clinicopathological variables and the MSI mode of MSI in endometrial cancer

\begin{tabular}{|c|c|c|c|c|}
\hline & \multicolumn{3}{|c|}{ MSI mode } & \multirow[t]{2}{*}{$p$ value } \\
\hline & Type A & Type B & negative & \\
\hline Number of cases & 8 & 30 & 56 & \\
\hline \multicolumn{5}{|l|}{ Age } \\
\hline$<55$ & 8 & 18 & 24 & \multirow[t]{2}{*}{0.01} \\
\hline$>56$ & 0 & 12 & 32 & \\
\hline \multicolumn{5}{|l|}{ Stage } \\
\hline 1 & 5 & 21 & 39 & \multirow[t]{4}{*}{0.76} \\
\hline 2 & 0 & 0 & 2 & \\
\hline 3 & 3 & 7 & 14 & \\
\hline 4 & 0 & 2 & 1 & \\
\hline \multicolumn{5}{|l|}{ Grade } \\
\hline 1 & 2 & 12 & 23 & \multirow[t]{3}{*}{0.65} \\
\hline 2 & 3 & 11 & 24 & \\
\hline 3 & 3 & 7 & 9 & \\
\hline \multicolumn{5}{|l|}{ Survival } \\
\hline Alive & 8 & 28 & 47 & \multirow[t]{2}{*}{0.36} \\
\hline Dead & 0 & 2 & 9 & \\
\hline \multicolumn{5}{|l|}{ Family history } \\
\hline \multicolumn{5}{|l|}{ Any cancer } \\
\hline Yes & 3 & 20 & 30 & \multirow[t]{2}{*}{0.26} \\
\hline No & 5 & 10 & 26 & \\
\hline \multicolumn{5}{|l|}{ Colorectal cancer } \\
\hline Yes & 1 & 7 & 3 & \multirow[t]{2}{*}{0.04} \\
\hline No & 7 & 23 & 53 & \\
\hline \multicolumn{5}{|l|}{ Gastric cancer } \\
\hline Yes & 0 & 11 & 16 & \multirow[t]{2}{*}{0.14} \\
\hline No & 8 & 19 & 40 & \\
\hline \multicolumn{5}{|c|}{ HNPCC-associated cancers ${ }^{\mathrm{a}}$} \\
\hline Yes & 1 & 16 & 16 & \multirow[t]{2}{*}{0.03} \\
\hline No & 7 & 14 & 40 & \\
\hline \multicolumn{5}{|l|}{ Double cancer } \\
\hline Yes & 0 & 4 & 12 & \multirow[t]{2}{*}{0.33} \\
\hline No & 8 & 26 & 44 & \\
\hline \multicolumn{5}{|l|}{ Menopause } \\
\hline Before & 3 & 11 & 19 & \multirow[t]{2}{*}{0.95} \\
\hline After & 5 & 19 & 37 & \\
\hline
\end{tabular}

a Carcinomas in the colorectum, endometrium, ovary and stomach were scored as 'HNPCC-associated cancers' (Vasen et al. 1999). The other HNPCC-related tumours were not found in the patients' kindred

Table $5 K R A S$ mutation and MSI-H/L

\begin{tabular}{llcc}
\hline & MSI-L & MSI-H & Subtotal \\
\hline KRAS & & & \\
Mutant & 1 & 4 & 5 \\
Wild type & 2 & 31 & 33 \\
Subtotal & 3 & 35 & 38 \\
\hline
\end{tabular}

$P=0.35$
Expression of one of the essential MMR genes, $M L H 1$, is known to be often lost in microsatellite-unstable ECs, primarily due to silencing by promoter methylation (Herman et al. 1998), and another essential MMR gene, $M S H 2$, has also been reported to be expressed at low levels in some previous studies (Hardisson et al. 2003; Ju et al. 2006; Peiro et al. 2002). Loss of expression of these essential MMR genes causes defective MMR in cells and, consequently, leads to a destabilisation of microsatellites on the genome. Using immunohistochemistry, we examined expression of MSH2 and MLH1 proteins in the EC tissues of our panel. Although both antigens were not detected in several cases, we found that loss of MLH1 expression was observed in the majority of $\mathrm{MSI}^{+}$tumours (22/36), whereas being significantly less frequent in microsatellite-stable tumours $(4 / 51, p<0.01)$. We further examined whether MLH1 silencing is more closely associated with any of the MSI subcategories. However, MLH1 expression loss was similarly frequent both in Type B and in MSI-H tumours, and therefore, the correlations were not significantly different between the two classifications (data not shown). Contrary to the results of the MLH1 immunohistochemistry, MSH2 expression loss was similarly infrequent both in $\mathrm{MSI}^{+}$tumours and in those with stable microsatellites and, consequently, not associated with the $\mathrm{MSI}^{+}$phenotype (data not shown).

\section{Discussion}

Numerous studies have been done on the microsatellite alterations observed in human ECs to date. Supplementary Table provides a summary of the literature. Studies of various sizes have been conducted on various subjects of different histological subtypes and genetic backgrounds, and the reported frequency for $\mathrm{MSI}^{+}$tumours varies from 10 to $100 \%$, even if confined to the studies about endometrioid-type tumours in the sporadic setting. This variability in results may not be explicable merely from the variety of the subjects (Supplementary Table). As mentioned above, the reported frequency of $\mathrm{MSI}^{+}$tumours in each malignancy is indeed diverse in the literature, and this confusion in the field has continued ever since. The variety of targets for analysis, i.e. microsatellites, will also undoubtedly lead to the variability in results. Although the NCI workshop in 1997 (Boland et al. 1998) recommended the 'working reference panel' comprising two mononucleotide and three dinucleotide microsatellites, various microsatellites, including tetranucleotide microsatellites, have in fact been used in the field (see Supplementary Table). Moreover, the MSI frequency differs widely even within the studies using only mononucleotide and dinucleotide microsatellites (Supplementary Table). We believe that, in addition to selection of 
Table 6 KRAS mutation and Type A/B MSI

\begin{tabular}{llcc}
\hline & Type A & Type B & Subtotal \\
\hline KRAS & & & \\
Mutant & 3 & 2 & 5 \\
Wild type & 5 & 28 & 33 \\
Subtotal & 8 & 30 & 38 \\
\hline
\end{tabular}

$P=0.05$

targets for analysis, methodological problems at least partly account for the variability in results. Microsatellite length changes are sometimes as small as one or two base pairs in mononucleotide or dinucleotide microsatellites. Such small sequence alterations are not detectable in electrophoresis with significant migration errors, or under the influence of TDT activity of thermostable DNA polymerases such as Taq, which adds one additional base to PCR products in a sequence-dependent manner. In addition, cell populations carrying microsatellite alterations are not always predominant in a given sample. However, it is difficult to detect less abundant PCR products in an assay system using autoradiography or silver staining, due to their nonlinear detection characteristics. We previously established a sensitive fluorescent technique in which all of these methodological problems are overcome, and, in the present study, this technique was applied to address microsatellite alterations in ECs. The overall frequency of $\mathrm{MSI}^{+}$tumours was $40 \%$, and several previous studies in the literature indeed reported similar frequencies (Furlan et al. 2006; Hardisson et al. 2003; Ohwada et al. 2002; Risinger et al. 2005) (Supplementary Table).

The $\mathrm{MSI}^{+}$phenotype is now connected to specific clinicopathological characteristics of tumours. In colorectal cancer, $\mathrm{MSI}^{+}$tumours more frequently occur in the proximal colon and often exhibit characteristic histopathological features such as poor/signet ring cell differentiation, mucin secretion and lymphocyte infiltration (Jass et al. 2002), which are currently known as 'MSI-H histology' (Umar et al. 2004). Patient outcomes are in general believed to be more favourable in $\mathrm{MSI}^{+}$colorectal carcinomas (Popat et al. 2005). Accordingly, various clinicopathological features of tumours have been examined and are regarded as associated with the $\mathrm{MSI}^{+}$phenotype in other human malignancies. In EC, tumour histology, grade, location, stage and patient survivals have been reported (Supplementary Table). These parameters did not correlate with MSI in this study (Tables 3, 4). The clinical and histopathological phenotypes of tumours are determined by highly complicated systems. Their relationships to MSI may therefore be more complex than hitherto suspected. MSI is now regarded as a molecular hallmark of LS. Indeed, more than $90 \%$ of LS tumours are $\mathrm{MSI}^{+}$(Liu et al. 1996), which implies that MSI well reflects molecular abnormalities underlying LS tumourigenesis. One important finding of the present study is that Type B MSI did significantly correlate with family history of HNPCC-associated cancers, and that, on the other hand, MSI-H did not. This may be partly because the MSI-H phenotype sometimes includes Type A tumours (see Table 1) and inevitably tends to be heterogeneous in terms of the mode of microsatellite alterations. The tight connection between Type B MSI and LS tumourigenesis may suggest a biological importance of Type $\mathrm{B}$ alterations and, in addition, a potential advantage of the Type A/B classification. The $\mathrm{MSI}^{+}$phenotype is also connected to various other genomic changes. Genetic instability observed in colorectal cancer has been regarded as deriving two mutually exclusive pathways, the chromosomal instability (CIN) pathway frequently associated with mutations in various oncogenes or tumour suppressors such as TP53 and the microsatellite instability (MIN) pathway, in which TP53 mutations are rare and, instead, mutations are found in genes harbouring mononucleotide repeats within their ORFs (Schwartz et al. 1999). The frequency for KRAS mutations in $\mathrm{MSI}^{+}$tumours has been controversial. Mutations in the KRAS oncogene were initially regarded as infrequent in $\mathrm{MSI}^{+}$tumours (Ionov et al. 1993; Salahshor et al. 1999; Samowitz et al. 2001). However, in our previous study, we have shown that KRAS mutations are indeed observed in microsatellite-unstable tumours and, more importantly, are relatively frequent in tumours exhibiting Type A MSI (Zhao et al. 2008). Also in this study, KRAS mutation was closely associated with Type A instability. We have previously demonstrated that Type A MSI is a direct consequence of defective MMR (Oda et al. 2005). A close association of Type A MSI with point mutations is highly consistent with the mutator phenotype in cells deficient in MMR (de Wind et al. 1995; Reitmair et al. 1997). These observations may thus suggest that the modal classification is biologically relevant.

Using HRFMA, we confirmed that endometrioid-type EC is the most microsatellite-unstable neoplasm among the human malignancies thus far tested. In general, the frequencies for MSI-H and MSI-L in colorectal cancer are 5-10 and 10-20 \%, respectively. The MSI-H phenotype is very rare in the other human neoplasms, and the most frequently observed microsatellite-unstable phenotypes are generally MSI-L. Nevertheless, the MSI-H phenotype predominates in our panel of ECs (Table 1). The frequency for MSI-H exceeded $30 \%$. The MSI-H phenotype is typical of LS (Liu et al. 1996). The high frequency of this phenotype in endometrioid-type EC may suggest that the majority of this subset of ECs arises from molecular backgrounds similar to those of LS or, in other words, via the MIN pathway. This hypothesis may be consistent with the consensus that mutations in TP53 are relatively infrequent in endometrioid-type EC (Yeramian et al. 2013), which are similarly regarded as rare in the MIN pathway of colorectal cancer (Ionov et al. 1993; Salahshor et al. 
1999; Samowitz et al. 2001; Simms et al. 1998). Tumourigenesis in this pathway has not yet been well understood. Destabilisation of repetitive motifs may disrupt the genes harbouring repeats such as TGFBR2, IGF2R, BAX, CASP5 etc (Schwartz et al. 1999). On the other hand, mutations in established oncogenes and tumour suppressor genes and chromosomal instability leading to $\mathrm{LOH}$ in tumour suppressor loci are not hypothesised in the MIN pathway. Tumourigenesis without this classical model is still enigmatic. Type B MSI is observed in tumours exhibiting the MSI-H phenotype (Ikeda et al. 2001). This has been confirmed also in the present study (Table 2). Type B MSI indeed predominates in microsatellite-unstable ECs (Table 1). Our previous study suggests that defective MMR may be a promoting and, consequently, highly coincidental (as typical in Lynch syndrome patients), but insufficient factor for Type B changes, whereas being necessary and sufficient for Type A instability. In other words, whereas Type A MSI is a direct consequence of defective MMR, molecular abnormalities in addition to MMR deficiency may contribute to Type B alterations of microsatellites (Oda et al. 2005). Frequent Type B instability in endometrioid ECs suggests the possibility that this malignancy may provide a clue to Type B mechanisms and also serve as a good model for the MIN pathway tumourigenesis. Further analyses of the EC genome warrant particular attention.

\begin{abstract}
Acknowledgments We are most grateful to P. Karran and M. Sekiguchi for their helpful advice. The expert assistance in DNA extraction, DNA fragment analyses and sequencing by Y. Ogata, M. Hanaki, S. Kato, Y. Baba, K. Miyamoto, Y. Ikematsu and K. Funatsu is also gratefully acknowledged. This study was supported by a Grant-in-aid for Cancer Research from the Ministry of Health, Labour and Welfare and grants from the Ministry of Education, Culture, Sports, Science and Technology of Japan.
\end{abstract}

\section{Compliance with ethical standards}

Conflict of interest The authors have no conflicts of interest.

Ethical approval Ethical approval for this retrospective study was obtained from the institutional review board of NKCC.

Informed consent Written informed consent was obtained from each individual participant.

Open Access This article is distributed under the terms of the Creative Commons Attribution 4.0 International License (http://creativecommons.org/licenses/by/4.0/), which permits unrestricted use, distribution, and reproduction in any medium, provided you give appropriate credit to the original author(s) and the source, provide a link to the Creative Commons license, and indicate if changes were made.

\section{References}

Aaltonen LA, Peltomaki P, Leach FS, Sistonen P, Pylkkanen L, Mecklin JP, Jarvinen H, Powell SM, Jen J, Hamilton SR et al (1993)
Clues to the pathogenesis of familial colorectal cancer. Science 260(5109):812-816

Arzimanoglou II, Gilbert F, Barber HR (1998) Microsatellite instability in human solid tumors. Cancer 82(10):1808-1820

Boland CR, Thibodeau SN, Hamilton SR, Sidransky D, Eshleman JR, Burt RW, Meltzer SJ, Rodriguez-Bigas MA, Fodde R, Ranzani GN et al (1998) A National Cancer Institute Workshop on Microsatellite Instability for cancer detection and familial predisposition: development of international criteria for the determination of microsatellite instability in colorectal cancer. Cancer Res 58(22):5248-5257

de Wind N, Dekker M, Berns A, Radman M, te Riele H (1995) Inactivation of the mouse Msh2 gene results in mismatch repair deficiency, methylation tolerance, hyperrecombination, and predisposition to cancer. Cell 82(2):321-330

Duggan BD, Felix JC, Muderspach LI, Tourgeman D, Zheng J, Shibata D (1994) Microsatellite instability in sporadic endometrial carcinoma. J Natl Cancer Inst 86(16):1216-1221

Fujii K, Miyashita K, Yamada Y, Eguchi T, Taguchi K, Oda Y, Oda S, Yoshida MA, Tanaka M, Tsuneyoshi M (2009) Simulation-based analyses reveal stable microsatellite sequences in human pancreatic cancer. Cancer Genet Cytogenet 189(1):5-14

Furlan D, Carnevali I, Marcomini B, Cerutti R, Dainese E, Capella C, Riva C (2006) The high frequency of de novo promoter methylation in synchronous primary endometrial and ovarian carcinomas. Clin Cancer Res 12(11 Pt 1):3329-3336

Goel A, Arnold CN, Niedzwiecki D, Chang DK, Ricciardiello L, Carethers JM, Dowell JM, Wasserman L, Compton C, Mayer RJ et al (2003) Characterization of sporadic colon cancer by patterns of genomic instability. Cancer Res 63(7):1608-1614

Hardisson D, Moreno-Bueno G, Sanchez L, Sarrio D, Suarez A, Calero F, Palacios J (2003) Tissue microarray immunohistochemical expression analysis of mismatch repair (hMLH1 and $\mathrm{hMSH} 2$ genes) in endometrial carcinoma and atypical endometrial hyperplasia: relationship with microsatellite instability. Mod Pathol 16(11):1148-1158

Hawkins NJ, Tomlinson I, Meagher A, Ward RL (2001) Microsatellite-stable diploid carcinoma: a biologically distinct and aggressive subset of sporadic colorectal cancer. $\mathrm{Br} \mathrm{J}$ Cancer 84(2):232-236

Herman JG, Umar A, Polyak K, Graff JR, Ahuja N, Issa JP, Markowitz S, Willson JK, Hamilton SR, Kinzler KW et al (1998) Incidence and functional consequences of hMLH1 promoter hypermethylation in colorectal carcinoma. Proc Natl Acad Sci USA 95(12):6870-6875

Ikeda Y, Oda S, Abe T, Ohno S, Maehara Y, Sugimachi K (2001) Features of microsatellite instability in colorectal cancer: comparison between colon and rectum. Oncology 61(2):168-174

Ionov Y, Peinado MA, Malkhosyan S, Shibata D, Perucho M (1993) Ubiquitous somatic mutations in simple repeated sequences reveal a new mechanism for colonic carcinogenesis. Nature 363(6429):558-561

Jass JR, Walsh MD, Barker M, Simms LA, Young J, Leggett BA (2002) Distinction between familial and sporadic forms of colorectal cancer showing DNA microsatellite instability. Eur J Cancer 38(7):858-866

Ju W, Park HM, Lee SN, Sung SH, Kim SC (2006) Loss of hMLH1 expression is associated with less aggressive clinicopathological features in sporadic endometrioid endometrial adenocarcinoma. J Obstet Gynaecol Res 32(5):454-460

Kolodner RD, Hall NR, Lipford J, Kane MF, Rao MR, Morrison P, Wirth L, Finan PJ, Burn J, Chapman P (1994) Structure of the human MSH2 locus and analysis of two Muir-Torre kindreds for msh2 mutations. Genomics 24(3):516-526

Kolodner RD, Hall NR, Lipford J, Kane MF, Morrison PT, Finan PJ, Burn J, Chapman P, Earabino C, Merchant E (1995) Structure 
of the human MLH1 locus and analysis of a large hereditary nonpolyposis colorectal carcinoma kindred for mlh1 mutations. Cancer Res 55(2):242-248

Lagarda H, Catasus L, Arguelles R, Matias-Guiu X, Prat J (2001) $\mathrm{K}$-ras mutations in endometrial carcinomas with microsatellite instability. J Pathol 193(2):193-199

Lengauer C, Kinzler KW, Vogelstein B (1998) Genetic instabilities in human cancers. Nature 396(6712):643-649

Liu B, Parsons R, Papadopoulos N, Nicolaides NC, Lynch HT, Watson P, Jass JR, Dunlop M, Wyllie A, Peltomaki P et al (1996) Analysis of mismatch repair genes in hereditary non-polyposis colorectal cancer patients. Nature Med 2(2):169-174

Maehara Y, Oda S, Sugimachi K (2001) The instability within: problems in current analyses of microsatellite instability. Mutation Res 461(4):249-263

Oda S, Oki E, Maehara Y, Sugimachi K (1997) Precise assessment of microsatellite instability using high resolution fluorescent microsatellite analysis. Nucleic Acids Res 25(17):3415-3420

Oda S, Maehara Y, Ikeda Y, Oki E, Egashira A, Okamura Y, Takahashi I, Kakeji Y, Sumiyoshi Y, Miyashita K et al (2005) Two modes of microsatellite instability in human cancer: differential connection of defective DNA mismatch repair to dinucleotide repeat instability. Nucleic Acids Res 33(5):1628-1636

Ohwada M, Suzuki M, Kohno T, Saga Y, Takei Y, Jobo T, Kuramoto $\mathrm{H}$, Sato I (2002) Involvement of microsatellite instability in lymph node metastasis of endometrial carcinoma. Cancer Genet Cytogenet 132(2):152-155

Oki E, Oda S, Maehara Y, Sugimachi K (1999) Mutated gene-specific phenotypes of dinucleotide repeat instability in human colorectal carcinoma cell lines deficient in DNA mismatch repair. Oncogene 18(12):2143-2147

Peiro G, Diebold J, Lohse P, Ruebsamen H, Baretton GB, Lohrs U (2002) Microsatellite instability, loss of heterozygosity, and loss of hMLH1 and hMSH2 protein expression in endometrial carcinoma. Hum Pathol 33(3):347-354

Popat S, Hubner R, Houlston RS (2005) Systematic review of microsatellite instability and colorectal cancer prognosis. J Clin Oncol 23(3):609-618

Reitmair AH, Risley R, Bristow RG, Wilson T, Ganesh A, Jang A, Peacock J, Benchimol S, Hill RP, Mak TW et al (1997) Mutator phenotype in Msh2-deficient murine embryonic fibroblasts. Cancer Res 57(17):3765-3771

Risinger JI, Maxwell GL, Chandramouli GV, Aprelikova O, Litzi T, Umar A, Berchuck A, Barrett JC (2005) Gene expression profiling of microsatellite unstable and microsatellite stable endometrial cancers indicates distinct pathways of aberrant signaling. Cancer Res 65(12):5031-5037

Salahshor S, Kressner U, Pahlman L, Glimelius B, Lindmark G, Lindblom A (1999) Colorectal cancer with and without microsatellite instability involves different genes. Genes Chromosomes Cancer 26(3):247-252

Samowitz WS, Holden JA, Curtin K, Edwards SL, Walker AR, Lin HA, Robertson MA, Nichols MF, Gruenthal KM, Lynch BJ et al (2001) Inverse relationship between microsatellite instability and K-ras and p53 gene alterations in colon cancer. Am J Pathol 158(4):1517-1524

Schwartz S Jr, Yamamoto H, Navarro M, Maestro M, Reventos J, Perucho M (1999) Frameshift mutations at mononucleotide repeats in caspase- 5 and other target genes in endometrial and gastrointestinal cancer of the microsatellite mutator phenotype. Cancer Res 59(12):2995-3002

Simms LA, Radford-Smith G, Biden KG, Buttenshaw R, Cummings M, Jass JR, Young J, Meltzer SJ, Leggett BA (1998) Reciprocal relationship between the tumor suppressors $\mathrm{p} 53$ and BAX in primary colorectal cancers. Oncogene 17(15):2003-2008

Umar A, Boland CR, Terdiman JP, Syngal S, de la Chapelle A, Ruschoff J, Fishel R, Lindor NM, Burgart LJ, Hamelin R et al (2004) Revised Bethesda Guidelines for hereditary nonpolyposis colorectal cancer (Lynch syndrome) and microsatellite instability. J Natl Cancer Inst 96(4):261-268

Vasen HF, Watson P, Mecklin JP, Lynch HT (1999) New clinical criteria for hereditary nonpolyposis colorectal cancer (HNPCC, Lynch syndrome) proposed by the International Collaborative group on HNPCC. Gastroenterology 116(6):1453-1456

Yeramian A, Moreno-Bueno G, Dolcet X, Catasus L, Abal M, Colas E, Reventos J, Palacios J, Prat J, Matias-Guiu X (2013) Endometrial carcinoma: molecular alterations involved in tumor development and progression. Oncogene 32(4):403-413

Young J, Simms LA, Biden KG, Wynter C, Whitehall V, Karamatic R, George J, Goldblatt J, Walpole I, Robin SA et al (2001) Features of colorectal cancers with high-level microsatellite instability occurring in familial and sporadic settings: parallel pathways of tumorigenesis. Am J Pathol 159(6):2107-2116

Zhao Y, Miyashita K, Ando T, Kakeji Y, Yamanaka T, Taguchi K, Ushijima T, Oda S, Maehara Y (2008) Exclusive KRAS mutation in microsatellite-unstable human colorectal carcinomas with sequence alterations in the DNA mismatch repair gene, MLH1. Gene 423(2):188-193 